\title{
Temporal control on periodic schedules: Fine structure
}

\author{
J. E. R. STADDON and JANICE A. FRANK \\ Duke University, Durham, North Carolina 27706
}

\begin{abstract}
The temporal pattern of the terminal response on periodic schedules depends on when responding begins. Pigeons pecking on fixed-interval and fixed-time schedules of food reinforcement responded, or accelerated, faster the later in an interval they began responding.
\end{abstract}

If small portions of food are delivered to a hungry animal at fixed time intervals, most species soon develop a pattern of behavior that is in step with the periodic food (e.g., Killeen, 1975; Staddon \& Simmelhag, 1971). Once behavior has stabilized, it can conveniently be divided into two classes: the terminal response is the activity which increases monotonically with post-food time and is usually occurring at the time of food delivery; the interim activities generally follow a bitonic time course, and are usually not occurring when food is delivered. In pigeons, pecking is a common terminal response, especially if the animal has already learned to peck for food in the Skinner box, if food delivery is very frequent, if food portions are large, or if the animal is very hungry. Common interim activities are pacing, jumping, and wingflapping.

On periodic schedules, the terminal response usually begins about one-half to two-thirds the way through the interfood interval (Schneider, 1969), but there is always some variation in its time of onset and patterning from interval to interval. The present experiment is concerned directly with a detailed analysis of variation in terminal keypecking by pigeons. In addition to its taxonomic interest, such an analysis sheds light on the interactions among interim and terminal responses on periodic schedules generally.

\section{METHOD}

\section{Subjects}

Seven adult male, White Carneaux pigeons, maintained at $80 \%$ of their free-feeding weights, were used. All had considerable experience on a variety of fixed-interval and fixed-time schedules before exposure to the procedures discussed here.

\section{Procedure}

All the animals were run until stable on fixed-interval (birds $40,71,72,133$, and 135 on FI 33 sec; birds 134 and 136 on FI $120 \mathrm{sec}$ ) or fixed-time (birds 40,71, and 72 on FT $33 \mathrm{sec}$ )

\footnotetext{
This research was supported by a grant from the National Science Foundation to Duke University. These data were presented at the Fall 1974 meeting of the Psychonomic Society, Boston, Massachusetts. Reprints may be obtained from J. E. R. Staddon, Department of Psychology. Duke University, Durham, North Carolina 27706.
}

schedules of food reinforcement. (On FI $t$ sec, the first keypeck $t$ sec after food delivery procured 3-sec access to mixed grain; on FT $t$, the bird received 3-sec access every $t \mathrm{sec}$, independently of its behavior.) Sessions terminated after approximately 60 food deliveries, and the animals were run 5 days a week. Scheduling was carried out by conventional electromechanical relays, timers, and pulse formers.

Cumulative response records were taken, as well as total session times and numbers of keypecks and food deliveries. Keypeck and food delivery data for selected days of stable responding were also recorded on an eight-channel punched paper-tape data multiplexing system that allowed determination of the times of onset and offset of events to $1 / 16 \mathrm{sec}$. These tapes were later analyzed with the aid of a PDP-8/L minicomputer.

\section{RESULTS}

\section{Data Analysis}

Pooled data for 5 days of stable responding under each condition were analyzed in two ways: (a) The time to first keypeck (pause) in each interval was computed and relative frequency distributions obtained. These are the small bitonic functions in Figures 1 and 2. (b) Intervals were sorted according to the pause in that interval. Thus, on FI $33 \mathrm{sec}$, intervals in which responding began in the first $3 \mathrm{sec}$ (Cell 1), the second $3 \mathrm{sec}$ (Cell 2), and so on were classified separately. The cell width, $m$, was approximately 1/10th the interval duration: $3 \mathrm{sec}$ for FI and FT $33 \mathrm{sec}, 12 \mathrm{sec}$ for FI $120 \mathrm{sec}$. Within a category (i.e., for all intervals in which responding began in a given cell), responses in successive $\mathrm{m}$-sec periods after the first response were sorted into cells. Thus, for a FI 33-sec interval in which the first response occurred $11-5 / 16 \mathrm{sec}$ after food, responses in seconds $11-5 / 16$ through $14-4 / 16,14-5 / 16$ through $17-4 / 16$, and so on, were accumulated in Cells 1 to $\mathrm{L}$, where $L$ equals the integer part of $t / m$, and $t$ is the interval length and $m$ the cell width. These data show the average response rate as a function of time since the first response in an interval, with the time of the first response (pause) as a parameter. The families of curves in Figures 1 and 2 show these functions with the starting point of each curve corresponding to the pause category. Thus, the curve beginning at Cell 3, on FI $33 \mathrm{sec}$, shows the average response rate in 


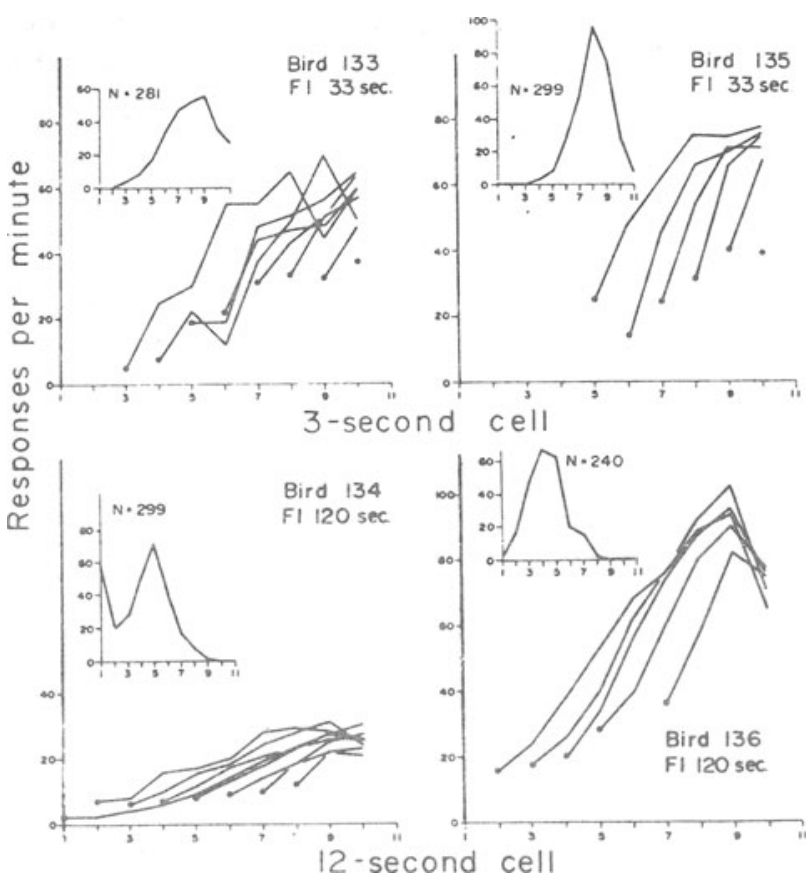

Figure 1. Insets: Distributions of time to first response (pause) within an interval for 5 days of stable responding on two fixed-interval schedules for four pigeons. Curves: Response rate in successive 3-sec (FI 33 sec) or 12-sec (FI 120 sec) periods following pauses of different lengths. Pause length is indicated by the cell in which the first point falls.

successive 3 -sec intervals following first responses between 6 and $9 \mathrm{sec}$ after the end of food delivery.

Figure 1 shows data from four pigeons, two trained on FI $33 \mathrm{sec}$, two on FI $120 \mathrm{sec}$. The pause distributions are typical of FI schedules and show most pauses to be between one-half and three-quarters of the interval in length. The response rate data show two kinds of dependence of rate on pause. For some birds (particularly 133, and to a lesser extent 135), initial response rate (i.e., rate in the first $\mathrm{m}$ sec after responding begins) increases with pause duration: the later in the interval the bird begins to respond, the faster he goes (type A pattern). Other birds showed little dependence of initial rate on pause, but showed sharper acceleration after longer pauses: the later responding began in the interval, the more rapidly it accelerated (type $B$ pattern). This pattern is shown by birds 134 and 136 in Figure 1 . Both kinds of dependence result in a terminal rate (i.e., rate at the time of food delivery) that is approximately constant.

Figure 2 compares the pattern of responding on FI and FT schedules. As in Figure 1, there seem to be two kinds of dependence on time. Bird 72 shows a strong dependence of initial rate on pause; bird 71 shows an almost constant initial rate, but more rapid acceleration following longer pauses. Bird 40 is intermediate. The FI and FT patterns are very similar for each bird.

\section{DISCUSSION}

The response rate data in Figures 1 and 2 all show a strikingly precise dependence on time, with initial rate and/or rate of acceleration determined by starting time in such a way that approximately the same terminal rate is attained at the end of each interval. Independence, in this kind of plot, would mean that the various curves could be superimposed by sliding them along the abscissa. While this is possible for some neighboring curves for some animals (e.g., the last three or four curves for bird 71 on FI $33 \mathrm{sec}$ ), it is not possible for all.

There is some reason to suspect a quantitative difference between rats and pigeons in the fine structure of responding on periodic schedules. Harzem (personal communication) has looked at the relation between rate of responding after the first response in each interval (running rate) and pause. He finds that for rats running rate is directly related to pause, whereas for pigeons running rate is approximately constant. Figures 1 and 2 show both patterns. Data such as those for bird 134 on FI $120 \mathrm{sec}$ or bird 71 on FI or FT $33 \mathrm{sec}$, if averaged to yield running rate, show an almost constant running rate. Birds conforming to this type B pattern start at an almost constant rate and end up at an almost constant rate; hence their overall running rate is independent of pause. However, data such as those for bird 72 show an increasing initial rate and an almost constant terminal rate (type A pattern), hence a direct relation between pause and running rate. It is possible, therefore, that most pigeons approximate the type B pattern, whereas most rats conform to type $A$, and that this population difference is the basis of the difference found by Harzem.

Figure 2 shows very similar performances by each bird on the FI (response dependent) and FT (response independent) schedules. However, this similarity probably does not hold under all conditions-when longer intervals are used (e.g., Staddon \& Frank, 1975) or when exposure to the FT condition is protracted.

Several experiments have studied the interactions among activities induced by periodic food schedules. Their conclusions

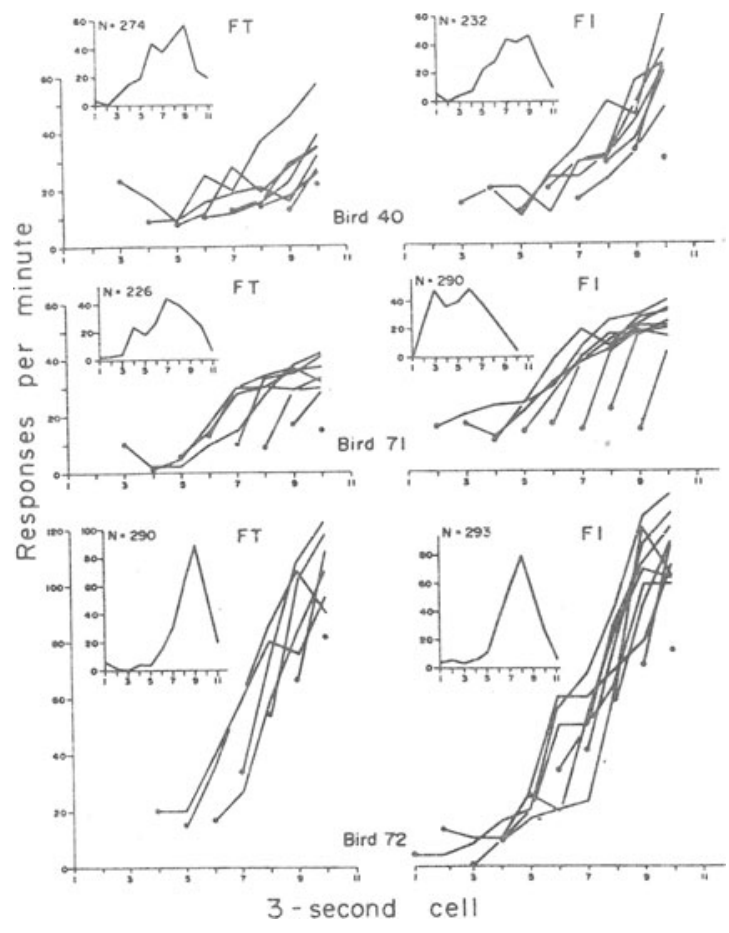

Figure 2. Stable data for three pigeons on fixed-interval and fixed-time 33-sec schedules. Details as in Figure 1. 
can be summarized as follows: (a) Disruption of interim activities (e.g., by removing supporting stimuli such as water bottles or running wheels, or by restricting bodily activity) causes the terminal response to begin earlier in the interval (Frank \& Staddon, 1974; Staddon \& Ayres, 1975). (b) Most of this disruption is transient. (c) Correlations between (i) the time of onset of an activity and its duration and (ii) the time between one activity and the next, and the duration of the first activity, are usually negative, for both rats and pigeons: the later the animal begins an activity in an interval, the shorter its duration, and the later he ends an activity, the shorter the time to the next activity (Staddon, 1972; Staddon \& Ayres, 1975).

These facts are consistent with the following simple hypothesis about the typical structure of behavior sequences induced by periodic food (Staddon, 1972, in press): (a) The tendencies to engage in various activities compete for access to the behavioral "final common path"; i.e., activities are reciprocally inhibitory. (b) The tendencies to engage in different activities peak at different times: interim activities tend to occur early in the interval, the terminal response later. Thus, the time of onset of the terminal response (for example) is jointly determined by an excitatory tendency that increases monotonically with post-food time and a suppressive effect of the ongoing interim activity that normally precedes it within each interval. If these two activities are denoted by $X$ and $Y$, then the shift from $X$ to $Y$ occurs when the temporal factors facilitating $Y$ outweigh the suppressive effects of $\mathrm{X}$ on $\mathrm{Y}$.

A simple algebraic model of this sort can obviously be implemented in a number of quantitative ways (e.g., Atkinson \& Birch, 1970; McFarland, 1974; Staddon, in press). However, the present data confirm one prediction of this type of model that can be made independently of quantitative details: that is, the time course followed by the terminal response should depend on its time of onset within the interfood interval. This is what we have found. For example, if the terminal response begins late in the interval, then the temporal excitatory factors should be strong and its initial rate, or rate of acceleration, should be higher than if it begins early in the interval when the temporal factors are weaker.

The present data also support earlier arguments (Frank \& Staddon, 1974; Staddon, 1972), ruling out a chaining interpretation of temporal control, since chaining implies that the postpause temporal pattern of responding should be invariant.

Although no provision was made for recording of specific interim activities in the present experiment, such activities are ubiquitous in pigeons on periodic schedules (Staddon \& Simmelhag, 1971), and it is therefore reasonable to assume that they occurred in this instance. On this assumption, the type $A$ and type $B$ patterns found suggest quantitatively different types of interaction between the terminal response and the preceding interim activity. The type A pattern is consistent with the idea that once the last interim activity is supplanted by the terminal response, within an interval, its strength rapidly falls to zero. Thus, the strength (rate) of the terminal response rises quickly to a level determined solely by temporal factors. It seems reasonable to suppose that these factors are increasing with post-food time, so that the initial rate of the terminal response is higher, the later it begins in the interval. However, the type B pattern may result if the strength of the last interim activity falls relatively slowly to zero after it is supplanted by the terminal response. In this case, the initial strength (rate) of the terminal response will be determined by the difference between the contribution due to temporal factors and the nonzero strength of the tendency to engage in the interim activity that has just ceased. Depending on the relative slope of these two functions (temporal factors controlling the terminal response and the declining strength of the interim activity), a more or less constant initial terminal response rate will result. Once the strength of the interim activity falls to zero, however, the terminal response will be determined solely by temporal factors, as in the type A case, so that the final terminal rate will be roughly constant for both patterns.

\section{REFERENCES}

Atkinson, J. W.. \& Birch, D. The dynamics of action. New York: Wiley, 1970.

Frank, J.. \& Staddon, J. E. R. Effects of restraint on temporal discrimination behavior. Psychological Record, 1974. 24, 123-130.

Killeen, P. On the temporal control of behavior. Psychological Review, 1975, 82, 89-115.

MCFARLAND. D. J. Time-sharing as a behavioral phenomenon. In D. S. Lehrman. J. S. Rosenblatt. R. A. Hinde, \& E. Shaw (Eds.). Advances in the study of behavior (Vol. 5). New York: Academic Press, 1974. Pp. 201-225.

SCHNEIDER, B. A. A two-state analysis of fixed-interval responding in the pigeon. Joumal of the Experimental Analysis of Behavior, 1969, 12, 677-687.

StadDon. J. E. R. A note on the analysis of behavioral sequences in Columba livia. Animal Behaviour. 1972. 20. 284-292.

Staddon, J. E. R. Schedule-induced behavior. In W. K. Honig \& J. E. R. Staddon (Eds.), Handbook of operant behavior. Englewood Cliffs, N.J: Prentice Hall, 1976 (in press).

StadDon. J. E. R.. \& AYres, S. L. Sequential and temporal properties of behavior induced by a schedule of periodic food delivery. Behaviour. 1975, in press.

Staddon, J. E. R., \& Frank, J. A. The role of the peck-food contingency on fixed-interval schedules. Journal of the Experimental Analysis of Behavior, 1975, 23, 17-23.

Staddon, J. E. R., \& Simmelhag, V. L. The "superstition" experiment: A re-examination of its implications for the principles of adaptive behavior. Psychological Review, 1971, 78, 3-43.

(Received for publication July 18, 1975.) 